\title{
Microscopia e morfometria de componentes tubulares de testículos de coelhos suplementados com geleia real
}

\author{
[Microscopy and morphometry of tubular components of rabbit testis supplemented with royal jelly] \\ D.B. Morais ${ }^{1}$, L.P. Barbosa ${ }^{2 *}$, B.E.S. Melo ${ }^{1}$, S.L.P. Matta ${ }^{1}$, M.M. Neves ${ }^{1}$, \\ M.K. Balarini ${ }^{1}$, M.V. Rodrigues ${ }^{1}$ \\ ${ }^{1}$ Universidade Federal de Viçosa - Viçosa, MG \\ ${ }^{2}$ Universidade Federal do Recôncavo da Bahia - Cruz das Almas, Ba
}

\begin{abstract}
RESUMO
Estudaram-se os efeitos da geleia real sobre a espermatogênese de coelhos tratados com diferentes concentrações de geleia real. Os tratamentos foram formados por três grupos: grupo-controle; grupo que recebeu $0,5 \mathrm{mg} / \mathrm{dia}$ de geleia real; e grupo que recebeu $1,0 \mathrm{mg} / \mathrm{dia}$ de geleia real. O estudo envolveu a morfometria testicular. Não houve diferença entre os tratamentos quanto aos pesos corporal $(\mathrm{T} 1=3,20 \pm 0,19 \mathrm{~kg}, \mathrm{~T} 2=2,96 \pm 0,30 \mathrm{~kg}$ e $\mathrm{T} 3=3,21 \pm 0,37 \mathrm{~kg})$ e gonadal $(\mathrm{T} 1=2,36 \pm 0,33 \mathrm{~g}, \mathrm{~T} 2=2,53 \pm 0,33 \mathrm{~g}$ e $\mathrm{T} 3=2,64 \pm 0,39 \mathrm{~g})$ e quanto aos índices gonadossomático $(\mathrm{T} 1=0,15 \pm 0,02 \%, \mathrm{~T} 2=0,17 \pm 0,03 \%$ e $\mathrm{T} 3=0,16 \pm 0,02 \%)$ e tubulossomático $(\mathrm{T} 1=0,06 \pm 0,01 \%$; $\mathrm{T} 2=0,07 \pm 0,01 \%$ e $\mathrm{T} 3=0,06 \pm 0,01 \%)$. O diâmetro médio dos túbulos seminíferos ( $\mathrm{T} 1=225,95 \pm 13,27 \mu \mathrm{m}, \mathrm{T} 2=239,68 \pm 21,50 \mu \mathrm{m}$ e T3=231,57 $\pm 15,94 \mu \mathrm{m})$, a altura do epitélio seminífero (T1=66,05 $\pm 5,37 \mu \mathrm{m}, \mathrm{T} 2=73,47 \pm 9,11 \mu \mathrm{m}$ e $\mathrm{T} 3=63,34 \pm 4,79 \mu \mathrm{m})$ e o comprimento de túbulos seminíferos por testículo $(\mathrm{T} 1=46,63 \pm 13,44 \mathrm{~m}, \mathrm{~T} 2=43,58 \pm 12,17 \mathrm{~m} \quad \mathrm{e}$ $\mathrm{T} 3=46,96 \pm 9,54 \mathrm{~m})$ e por grama de testículo $(\mathrm{T} 1=19,50 \pm 2,68 \mathrm{~m}, \mathrm{~T} 2=17,12 \pm 3,91 \mathrm{~m}$ e T3=17,78 $\pm 1,98 \mathrm{~m})$ não diferiram entre tratamentos. Conclui-se que a suplementação com geleia real, nas doses utilizadas, não altera as características testiculares avaliadas.
\end{abstract}

Palavras-chave: coelho, espermatogênese, compartimento tubular, túbulos seminíferos, epitélio seminífero

\begin{abstract}
This study aimed to investigate the effects of royal jelly on spermatogenesis in rabbits treated with different concentrations of RJ (Control; 0,5mg/day; and 1,0mg/day) using testicular morphometry. There was no significant difference between the body weight $(T 1=3.20 \pm 0.19 \mathrm{~kg} ; T 2=2.96 \pm 0.30 \mathrm{~kg}$; $T 3=3.21 \pm 0.37 \mathrm{~kg})$ and gonadal weight $(T 1=2.36 \pm 0.33 \mathrm{~g} ; T 2=2.53 \pm 0.33 \mathrm{~g} ; \mathrm{T3}=2.64 \pm 0.39 \mathrm{~g})$, gonadossomatic index $(T 1=0.15 \pm 0.02 \% ; T 2=0.17 \pm 0.03 \% . T 3=0.16 \pm 0.02 \%)$ and tubulossomatic index $(T 1=0.06 \pm 0.01 \% ; T 2=0.07 \pm 0.01 \% . T 3=0.06 \pm 0.01 \%)$ between treatments, showing that the percentage of body mass, and the percentage of seminiferous tubules allocated in testis were similar in the 3 experimental groups. Similarly, the mean diameter of the seminiferous tubules $(T 1=225.95 \pm 13.27 \mu m$; $T 2=239.68 \pm 21.50 \mu \mathrm{m} ; \quad T 3=231.57 \pm 15,94 \mu \mathrm{m})$, the height of the seminiferous epithelium $(T 1=66,05 \pm 5,37 \mu \mathrm{m} ; T 2=73.47 \pm 9.11 \mu \mathrm{m} ; \mathrm{T3}=63.34 \pm 4.79 \mu \mathrm{m})$ and length of seminiferous tubule for testis $(T 1=46.63 \pm 13.44 \mathrm{~m} ; T 2=43.58 \pm 12.17 \mathrm{~m} ; T 3=46.96 \pm 9.54 \mathrm{~m})$ and per gram of testis $(T 1=19.50 \pm 2.68 \mathrm{~m}$; $T 2=17.12 \pm 3.91 \mathrm{~m} ; \mathrm{T} 3=17.78 \pm 1.98 \mathrm{~m}$ ) did not differ statistically. It was concluded that supplementation with royal jelly, at the doses used, did not alter the testicular parameters evaluated here.
\end{abstract}

Keywords: rabbit, spermatogenesis, tubular compartment, seminiferous tubule, seminiferous epithelium

Recebido em 5 de abril de 2011

Aceito em 8 de dezembro de 2011

* Autor para correspondência (corresponding author)

E-mail: larissa@ufrb.edu.br 


\section{INTRODUÇÃO}

Há tempos, produtos naturais, de origem animal ou vegetal, são empregados na medicina popular com a finalidade de prevenir e tratar doenças, embora sua eficácia não tenha ainda sido devidamente testada. Dentre esses compostos, pode-se citar a geleia real, uma secreção glandular produzida pelas abelhas operárias, que tem chamado a atenção devido à longevidade e fertilidade que confere à abelha rainha (SalazarOlivo e Paz-González, 2005), constituindo sua única fonte alimentar, desde seu estágio larval, bem como alimento exclusivo dessa casta (KoyaMyiata et al., 2004). Sabe-se que sua composição química é complexa, incluindo proteínas, carboidratos, lipídeos e vitaminas.

São atribuídas à geleia real diversas propriedades farmacológicas e nutricionais, tais como: efeito estrogênico (Mishima et al., 2005), antitumoral (Townsend et al., 1982), antienvelhecimento (Ionue et al., 2003), antialérgico (Oka et al., 2001) e hipoglicêmico (Kramer et al., 1977), além de seus efeitos mitogênicos e sobre o crescimento e a diferenciação celulares (KoyaMyiata et al., 2004; Salazar-Olivo e PazGonzález, 2005).

Ademais, vários estudos apontam efeitos positivos sobre o processo reprodutivo de ovelhas (Husein e Haddad, 2006), coelhas (Khattab et al., 1989) e humanos (Al-Masri, 1986). Há demonstrações de que a resposta ao estro e a taxa de prenhez foram melhoradas em ovelhas quando a geleia real foi administrada em conjunto com o tratamento de progesterona intravaginal (Kridli et al., 2003). Husein e Haddad (2006) verificaram que a geleia real produziu efeito semelhante aos produzidos pela gonadotrofina coriônica equina (eCG) sobre o ciclo estral de ovelhas, aumentando a expressão do estro, diminuindo o intervalo entre estros e aumentando a taxa de gestação. Resultados semelhantes foram observados também por Kridli et al. (2003) em ovelhas.

No entanto, há poucos relatos da sua influência sobre a reprodução em machos, sobretudo no que diz respeito à morfometria testicular. Alterações no processo espermatogênico podem ser diagnosticadas com base neste conjunto de análises, em que são comparados, entre outros parâmetros, pesos, diâmetros, volumes e comprimentos de células e de túbulos seminíferos. Morais (2007) verificou aumento do volume de células de Leydig no compartimento intertubular dos testículos de camundongos tratados com geleia real via intraperitoneal. Por haver poucos dados disponíveis relativos à ação da geleia real no trato reprodutor masculino, este trabalho teve o objetivo de investigar os efeitos desse produto sobre a espermatogênese de coelhos, analisando parâmetros biométricos testiculares, macro e microscópicos.

\section{MATERIAL E MÉTODOS}

Utilizaram-se 12 coelhos da raça Nova Zelândia adultos, que receberam água e ração ad libitum e foram suplementados com geleia real, via oral, por 90 dias consecutivos, período este que compreende, aproximadamente, dois ciclos espermatogênicos em coelhos (França e Russell, 1998). Os animais foram distribuídos aleatoriamente em três tratamentos experimentais. Os do tratamento 1 (controle, $\mathrm{n}=4$ ) receberam $1 \mathrm{~mL}$ de água via oral; os do tratamento $2(\mathrm{n}=5), 0,5 \mathrm{mg}$ de geleia real diluída em $1 \mathrm{~mL}$ de água via oral; e os do tratamento 3 $(\mathrm{n}=3), 1,0 \mathrm{mg}$ de geleia real diluída em $1 \mathrm{~mL}$ de água via oral.

Depois de anestesiados com tiopental sódico $(20 \mathrm{mg} / \mathrm{kg})$ e eutanasiados com cloreto de potássio $(100 \mathrm{mg} / \mathrm{kg})$, os animais foram pesados, e seus testículos coletados, pesados e fixados em formol tamponado $10 \%$ por $24 \mathrm{~h}$ e depois transferidos para álcool $70 \%$. Um dos testículos foi destinado às análises morfológicas e morfométricas. $\mathrm{O}$ testículo contralateral foi reservado para a avaliação dos valores da albugínea e do mediastino.

Fragmentos testiculares foram desidratados em série etanólica crescente $-70 \%, 80 \%, 90 \%, 95 \%$ e $100 \%$-, com trocas a cada $30 \mathrm{~min}$, procedendose à inclusão em glicol-metacrilato (Historesin, Leica $\left.^{\circledR}\right)$. Foram obtidas secções a $5 \mu \mathrm{m}$, feitas em micrótomo rotativo (Reichert-Jung, 2045), utilizando-se navalhas de vidro. As secções obtidas foram coradas com azul de toluidina/borato de sódio $1 \%$, montadas com Alkolan ${ }^{\circledR}$ e analisadas em microscópio de luz (Olympus BX-50). Após passagem pelo álcool $70 \%$, a albugínea e o mediastino do testículo contralateral foram cuidadosamente removidos, pesados separadamente e descontados do peso 
total dos testículos, para cálculo do peso líquido testicular, ou volume ocupado pelo parênquima testicular, o qual corresponde à parte funcional do órgão.

Em cada grupo experimental foram utilizados os pesos corporal e gonadal, para cálculo do índice gonadossomático (IGS), bem como o peso corporal e o volume dos túbulos seminíferos, para cálculo do índice tubulossomático (ITS). O IGS representa o percentual de massa corporal alocado em testículos e foi obtido inferindo-se do peso corporal o peso de ambos os testículos (IGS=peso gonadal/peso corporal*100). O ITS representa o percentual do peso corporal alocado em túbulos seminíferos. Calculou-se previamente o volume do túbulo seminífero a partir da fórmula: VTS=volume líquido do testículo $* \%$ túbulos seminíferos/100. Obteve-se, então, o ITS a partir da fórmula: ITS $=\mathrm{VTS} /$ peso corporal $* 100$.

Para a estimativa do diâmetro médio dos túbulos seminíferos, foram mensuradas 20 secções transversais de túbulos com o contorno mais circular possível. Para tanto, as medidas foram feitas sob microscopia de luz, utilizando-se o programa para análise de imagens Image Pro Plus, em aumento de 20x. As mesmas secções utilizadas para medir o diâmetro tubular foram utilizadas na mensuração da altura do epitélio seminífero, a qual foi tomada da túnica própria até o lúmen tubular. $\mathrm{O}$ valor encontrado para a altura do epitélio seminífero, em cada túbulo, representou a média de duas medidas tomadas de forma diametralmente opostas.

O comprimento dos túbulos seminíferos por testículo (CT), expresso em metros, foi estimado a partir do conhecimento do volume ocupado pelos túbulos seminíferos (VTS) no testículo e do diâmetro tubular médio obtido para cada animal, empregando-se a fórmula: $\mathrm{CT}=\mathrm{VTS} / \mathrm{JR}^{2}$, em que $\pi \mathrm{R}^{2}$ representa a área da secção transversal dos túbulos seminíferos ( $\mathrm{R}=$ diâmetro tubular/2). Para o cálculo do comprimento tubular por grama de testículo, dividiu-se o valor encontrado para o CT pelo peso testicular.

Foi utilizado o delineamento inteiramente ao acaso, e os dados foram analisados por meio de análise de variância, com $5 \%$ de probabilidade, utilizando-se o teste Tukey para comparar médias. Utilizou-se o software STATISTICA for Windows 3.11 .

\section{RESULTADOS E DISCUSSÃO}

O peso corporal médio apresentado pelos animais, segundo os tratamentos, encontra-se na Tab. 1.

Tabela 1. Dados biométricos de coelhos suplementados com geleia real in natura (média \pm desvio-padrão)

\begin{tabular}{lccc}
\multicolumn{1}{c}{ Característica } & $\begin{array}{c}\text { Sem geleia } \\
(\mathrm{n}=4)\end{array}$ & $\begin{array}{c}0,5 \mathrm{mg} \text { de geleia } \\
(\mathrm{n}=5)\end{array}$ & $\begin{array}{c}1,0 \mathrm{mg} \text { de geleia } \\
(\mathrm{n}=3)\end{array}$ \\
\hline Peso corporal $(\mathrm{kg})$ & $3,20 \pm 0,19$ & $2,96 \pm 0,30$ & $3,21 \pm 0,37$ \\
Peso testicular $(\mathrm{g})$ & $2,36 \pm 0,33$ & $2,53 \pm 0,33$ & $2,64 \pm 0,39$ \\
Peso albugínea (g) & $0,174 \pm 0,03$ & $0,180 \pm 0,04$ & $0,171 \pm 0,03$ \\
Percentual da albugínea & $7,37 \pm 0,71$ & $7,13 \pm 1,46$ & $6,58 \pm 1,24$ \\
Peso mediastino (g) & $0,06 \pm 0,01$ & $0,08 \pm 0,03$ & $0,12 \pm 0,03$ \\
Percentual do mediastino & $2,80 \pm 0,93$ & $3,29 \pm 1,89$ & $4,84 \pm 1,56$ \\
Peso albugínea + mediastino (g) & $0,24 \pm 0,02$ & $0,26 \pm 0,06$ & $0,30 \pm 0,05$ \\
Peso parênquima testicular (g) & $2,12 \pm 0,32$ & $2,27 \pm 0,34$ & $2,34 \pm 0,41$ \\
IGS (\%) & $0,15 \pm 0,02$ & $0,17 \pm 0,03$ & $0,16 \pm 0,02$ \\
\hline
\end{tabular}

IGS: índice gonadossomático.

Não houve diferença entre tratamentos pelo teste Tukey $(\mathrm{P}>0,05)$.

Morais et al. (2007) não observaram diferença ao estudarem os efeitos da geleia real sobre a espermatogênese em camundongos, assim como Kridli e Al-Khetib (2006), ao testaram os efeitos da mesma substância sobre a expressão do estro e a taxa de prenhez em ovelhas. Embora trabalhasse com plantas medicinais como possíveis interferentes testiculares, Gomes (2007) observou aumento no peso corporal médio de ratos adultos tratados com infusão de catuaba (Trichilia catigua), semelhante ao observado por Chieregatto (2005), nos testículos de ratos tratados com extratos de verga-teso (Anemopaegma arvense) e nos 
tratados com extrato de nó de cachorro (Heteropterys aphrodisiaca), também considerados afrodisíacos.

Os testículos apresentaram-se no escroto em todos os animais, localizados ventralmente ao ânus, assim como foi observado por Barone et al. (1973). Observou-se retração deles em direção à região abdominal no momento da contenção para a eutanásia.

A produção espermática é altamente correlacionada com o peso testicular, de modo que esta pode induzir a alterações no tamanho e no peso testiculares, sendo potencialmente uma forma de acessar a produção de espermatozoides (França e Russell, 1998). Os pesos testicular e do parênquima testicular também não sofreram alteração diante das diferentes concentrações administradas de geleia real $(\mathrm{P}>0,05)$. Os valores médios encontrados no presente estudo (Tab. 1) apresentaram-se um pouco abaixo do padrão encontrado por França e Russell (1998), que citaram peso testicular médio no coelho de $3,1 \mathrm{~g}$.

Segundo França e Russell (1998), a albugínea responde por cerca de $10 \%$ do testículo dos animais domésticos, e seu valor é consideravelmente menor no coelho $(5,0 \%)$, em caprinos $(5,9 \%)$ e no cão doméstico $(6,0 \%)$. Neste estudo, a albugínea correspondeu a 7,4\%; $7,1 \%$ e $6,6 \%$ dos testículos dos coelhos, nos grupos controle e tratados com $0,5 \mathrm{mg}$ e $1,0 \mathrm{mg}$ de geleia real, respectivamente. De acordo com Egbunike et al. (1981), em animais com testículos relativamente mais leves, a albugínea ocupa maior percentual do peso daquele órgão.

O mediastino correspondeu a $2,8 \% ; 3,3 \%$ e $4,8 \%$ dos testículos dos coelhos, respectivamente, nos grupos controle e tratados com $0,5 \mathrm{mg}$ e $1,0 \mathrm{mg}$ de geleia real (Tab. 1). Estes valores foram próximos aos encontrados por Menezes (2006) em queixada (Tayassu pecari), em que o mediastino correspondeu a $2,9 \%$ do testículo, e abaixo dos 5,5\% encontrados em capivaras (Hydrochoerus hydrochaeris) por Paula, (1999).

Chieregatto (2005) observou redução significativa no peso da albugínea, no testículo de ratos tratados com extrato de $H$. aphrodisiaca, e os maiores valores em relação ao grupocontrole foram constatados nos animais tratados com A. arvense. Neste estudo, não foi observada diferença significativa entre tratamentos $(\mathrm{P}>0,05)$ quanto aos pesos de albugínea e mediastino.

O IGS encontrado foi acima da média registrada para a maioria das espécies de mamíferos domésticos e silvestres até hoje estudadas. A média, $0,16 \%$, no entanto, não diferiu $(\mathrm{P}>0,05)$ entre tratamentos, demonstrando um percentual de massa corporal alocado em gônadas similar entre o grupo-controle e os grupos tratados. Morais et al. (2007) também não encontraram alteração no IGS de camundongos tratados com geleia real durante seu ciclo espermatogênico, o mesmo ocorrendo em Chieregatto (2005), enquanto Gomes (2007) observou redução do IGS de ratos tratados com infusão T. catigua.

O tamanho relativo dos testículos correlaciona-se funcionalmente com o sistema de acasalamento (Dixson, 1993); dessa forma, espécies de mamíferos em que a fêmea copula com vários machos, durante o período fértil do ciclo ovariano, apresentam índices gonadossomáticos mais altos em relação aos índices de espécies em que um único macho é responsável pela cópula. Isto se deve ao fato de, no primeiro caso, haver necessidade de maior produção espermática, uma vez que a competição pela fertilidade ocorre no interior do trato genital da fêmea. Assim, o maior IGS observado no coelho, que neste estudo foi de aproximadamente $0,16 \%$ - e que no camundongo foi de $0,60 \%$ (Morais et al., 2007), na capivara de $0,12 \%$ (Paula, 1999) e no o cão de $0,10 \%$ (Paula, 1992) em relação, por exemplo, ao lobo guará, 0,04\% (Bittencourt, 2003) e à onçaparda com 0,03\% (Guião-Leite, 2002), parece ser reflexo de seu comportamento reprodutivo, pois a coelha copula com mais de um macho durante o estro.

Os valores médios do diâmetro tubular, da altura do epitélio seminífero, do volume dos túbulos seminíferos, do comprimento dos túbulos seminíferos e do ITS dos animais encontram-se Tab. 2. Não foi observada diferença significativa entre os tratamentos $(\mathrm{P}>0,05)$. 
Tabela 2. Características da morfometria testicular de coelhos suplementados com geleia real in natura (média \pm desvio-padrão)

\begin{tabular}{lccc}
\hline \multicolumn{1}{c}{ Característica } & $\begin{array}{c}\text { Sem geleia } \\
(\mathrm{n}=4)\end{array}$ & $\begin{array}{c}0,5 \mathrm{mg} \text { de geleia } \\
(\mathrm{n}=5)\end{array}$ & $\begin{array}{c}1,0 \mathrm{mg} \text { de geleia } \\
(\mathrm{n}=3)\end{array}$ \\
\hline Diâmetro do túbulo seminífero $(\mu \mathrm{m})$ & $225,95 \pm 13,27$ & $239,68 \pm 21,50$ & $231,57 \pm 15,94$ \\
Altura do epitélio seminífero $(\mu \mathrm{m})$ & $66,05 \pm 5,37$ & $73,47 \pm 9,11$ & $63,34 \pm 4,79$ \\
Volume do túbulo seminífero $(\mathrm{mL})$ & $1,83 \pm 0,28$ & $1,91 \pm 0,33$ & $1,97 \pm 0,35$ \\
Comprimento de túbulos seminíferos por & $46,63 \pm 13,44$ & $43,58 \pm 12,17$ & $46,96 \pm 9,54$ \\
testículo $(m)$ & & & \\
Comprimento de túbulos seminíferos $(\mathrm{m})$ & $19,50 \pm 2,68$ & $17,12 \pm 3,91$ & $17,78 \pm 1,98$ \\
por grama de testículo & $0,06 \pm 0,01$ & $0,07 \pm 0,01$ & $0,06 \pm 0,01$ \\
ITS $(\%)$ & & & \\
\hline
\end{tabular}

ITS: índice tubulossomático.

Não houve diferença entre tratamentos pelo teste Tukey $(\mathrm{P}>0,05)$.

Existe grande variação no número e nas dimensões (diâmetro e comprimento) dos túbulos seminíferos nas diferentes espécies de mamíferos (França e Russell, 1998). Em pesquisas que envolveram a função testicular, a medida do diâmetro tubular é uma abordagem classicamente utilizada para indicar a atividade espermatogênica (Paula, 1999). Tal medida (Tab. 2) apresentou-se dentro dos limites médios observados na maioria dos mamíferos já estudados, em que se observa variação de 180 a

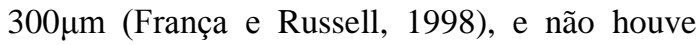
diferença significativa entre os tratamentos $(\mathrm{P}>0,05)$. Esta grande amplitude de diâmetro tubular entre os mamíferos pode ser observada entre raças, linhagens diferentes e sistemas de acasalamento, permanecendo, no entanto, relativamente constante em animais não sazonais e sexualmente maduros (Paula, 1999).

A altura do epitélio seminífero é uma característica efetiva para a avaliação da produção espermática, uma vez que acompanha as variações do ciclo do epitélio seminífero, como número de camadas do epitélio seminífero e de células mioides (Paula, 1999). Neste estudo, estes valores não apresentaram alterações entre os grupos experimentais $(\mathrm{P}>0,05)$ e também estiveram dentro da amplitude média para a maioria dos mamíferos, que é de 60 a $100 \mu \mathrm{m}$, segundo França e Russell (1998).

O volume médio de túbulos seminíferos foi de $1,83 \mathrm{~mL}, 1,91 \mathrm{~mL}$ e $1,97 \mathrm{~mL}$, para os grupos controle e tratados com $0,5 \mathrm{mg}$ e $1,0 \mathrm{mg}$ de geleia real, respectivamente, não sendo observada alteração significativa $(\mathrm{P}>0,05)$ entre tratamentos.
O comprimento dos túbulos seminíferos está relacionado a três parâmetros estruturais: tamanho do testículo, diâmetro tubular e volume dos túbulos seminíferos (França e Russell, 1998). O comprimento dos túbulos seminíferos por testículo (m) e seu comprimento por grama de testículo não diferiram entre os grupos $(\mathrm{P}>0,05)$. Resultado semelhante foi encontrado em camundongos tratados com geleia real, nos quais estas variáveis também não diferiram significativamente entre o grupo-controle e os tratamentos realizados, apresentando média de $15 \mathrm{~m}$ de túbulos seminíferos por grama de testículo (Morais, 2007). Os valores médios do comprimento de túbulos seminíferos por grama de testículo dos coelhos deste estudo não variaram estatisticamente e apresentaram-se um pouco acima da média encontrada para os mamíferos, que é de 10 a 15m, segundo França e Russell (1998).

No suíno doméstico, existem de várias centenas a alguns poucos milhares de túbulos seminíferos por testículo e aproximadamente $3000 \mathrm{~m}$ de túbulos no total para um peso testicular em torno de 300g (França e Russell, 1998), enquanto o coelho apresenta, em média, $62 \mathrm{~m}$, para um peso testicular médio de 3g (Amann, 1970). Essa quantificação métrica do túbulo seminífero por unidade de massa testicular, diferentemente da quantificação total, é um parâmetro produtivo que permite a comparação entre animais de diferentes portes (Sarti, 2006) e que, neste estudo, demonstrou que coelhos tratados com geleia real apresentam, em média, 36m de túbulo seminíferos, para um testículo de, aproximadamente, $2,5 \mathrm{~g}$. 
Ratos tratados com extrato aquoso de $T$. catigua também não apresentaram diferença no volume dos túbulos seminíferos e no comprimento tubular por testículo e por grama de testículo, apresentando valores de $29,71 \mathrm{~m}$ e $10,11 \mathrm{~m}$, respectivamente (Gomes, 2007), ao contrário do registrado por Chieregatto (2005) para as maiores doses de A. arvense e H. aphrodisiaca.

Assim como o IGS, o percentual de massa corporal alocada em túbulos seminíferos (ITS) também não sofreu alteração entre os grupos experimentais $(\mathrm{P}>0,05)$ (Tab. 2), demonstrando um investimento em túbulos seminíferos semelhante nos diferentes tratamentos empregados.

\section{CONCLUSÕES}

Não há alterações nas características de testículos de coelhos tratados com geleia real.

\section{AGRADECIMENTOS}

À Fundação de Amparo à Pesquisa do Estado de Minas Gerais (FAPEMIG), por financiar parte dos equipamentos e reagentes utilizados nesta pesquisa; ao Centro Universitário do Leste de Minas Gerais (Unileste-MG), por ceder as instalações do Biotério para manutenção dos animais; e ao Laboratório de Biologia Estrutural da Universidade Federal de Viçosa, onde foi realizado o processamento histológico do material.

\section{REFERÊNCIAS}

AL-MASRI, A. The Royal Jelly. Honeybee Kingdom and its derivation. Syria Arabic Book House Publishers, p.291-300, 1986.

AMANN, R.P. Sperm production rates. In: JOHNSON, A.D.; GOMES, R.; VANDEMARK, N.L. (Ed.). The testis. New York: Academic Press. v.1, 1970. p.433-482.

BARONE, R.; PAVAUX, C.; BLIN, P.C.; CUQ, P. Atlas d'anatomie du lapin. Paris: Masson, 1973. 219p.

BITTENCOURT, V.L. Avaliação morfofuncional do testículo e do processo espermatogênico do Lobo guará (Chrysocyon brachyurus, Illiger, 1811) adulto. 2003. 57f. Dissertação (Mestrado em Medicina Veterinária) - Departamento de Medicina Veterinária, Universidade Federal de Viçosa, Viçosa, 2003.
CHIEREGATTO, L.C. Efeito do tratamento crônico com extratos de Heteropterys aphrodiasiaca O. Mach. e Anemopaegma arvense (Vell) Stellf. no testículo de ratos Wistar adultos. 2005. 67f. Dissertação (Mestrado em Medicina Veterinária) - Departamento de Medicina Veterinária. Universidade Federal de Viçosa, Viçosa, 2005.

DIXSON, A.F. Sexual selection, sperm competition and the evolution of sperm length, Folia Primatol., v.61, p.221-227, 1993.

EGBUNIKE, G.N. Testis characteristics of pubertal large hite boars reared in a humid tropical environment. Andrologia, v.13, p.284-290, 1981.

FRANÇA, L.R.; RUSSELL, L.D. The testis of domestic mammals. In: MARTINEZ-GARCIA, F.; REGADERA, J. (Eds). Male reproduction - a multidisciplinary overview. Madrid: Churchill Communications, p.197-219. 1998.

GOMES, M.L.M. Morfometria testicular de ratos Wistar adultos tratados com infusão aquosa de catuaba (Trichila catigua A. Juss. Meliaceae). 2007. 38f. Dissertação (Mestrado em Biologia Celular e Estrutural) - Departamento de Biologia Geral. Universidade Federal de Viçosa, Viçosa, MG.

GUIÃO-LEITE, F.L. Análise morfológica do testículo e do processo espermatogênico da onça parda (Puma concolor) adulta. 2002. 64f. Dissertação (Mestrado) Universidade Federal de Viçosa, Viçosa, Viçosa, MG.

HUSEIN, M.Q.; HADDAD, S.G. A new approach to enhance reproductive performance in sheep using royal jelly in comparasion with equine chorionic gonadrotopin. Anim. Reprod. Sci., v.93, 24-33, 2006.

IONUE, S.I.; KOYA-MIYATA, S.; USHIO, S. et al. Royal jelly prolongs the life span of $\mathrm{C} 3 \mathrm{H} / \mathrm{H} 3 \mathrm{~J}$ mice: correlation with reduced DNA damage. Exp. Gerontol., v.38, p.965-969, 2003.

KHATTAB, M.M.; RADWAN, A.A.; AFIFI, E.A. Physiological effect of royal jelly on female reproductive capacity in rabbits. In: INTERNATIONAL CONGRESS APICULTURE IN TROPICAL CLIMATES, 4., 1989, Cairo, Egypt. Anais... London: IBRA, UK. 1989. p.6-10.

KOYA-MYIATA, S.; OKAMOTO, I.; USHIO, S. et al. Identification of a Collagen Production-promotion Factor from an Extract of Royal Jelly and its possible mechanism. Biosci., biotech., biochem., v.68, p.767773, 2004.

KRAMER, K.J.; TAGER, H.S.; CHILDS, C.N. et al. Insulin-like hypoglycemic and immunological activities in honeybee royal jelly. J. Insect Physiol., v.23, p.293-295, 1977. 
KRIDLI, R.T.; AL-KHETIB, S.S. Reproductive responses in ewes treated with eCG or increasing doses of royal jelly. Anim. Reprod. Sci., v.92, p.75-85, 2006.

KRIDLI, R.T.; HUSSEIN, M.G.; HUMPHREY, W.D. Effect of Royal Jelly and GnRH on the estrus synchronization and pregnancy rate in ewes using intravaginal sponges. Small Rum. Res., v.49, p.25-30, 2003.

MENEZES, C.M.C. Análise morfofuncional $d a$ espermatogênee de queixadas (Tayassu pecari LINK, 1795). 2006. 56f. Dissertação (Mestrado em Produção Animal) - Centro de Ciências e Tecnologias Agropecuárias. Universidade Federal do Norte Fluminense, Campos dos Goytacazes, 2006.

MISHIMA, S.; SUZUKI, K.M.; ISOHAMA, Y. et al. Royal jelly has estrogenic effects in vitro and in vivo. J. Ethnopharmacol., v.101, p.215-220, 2005.

MORAIS, A.C.T. Efeito da suplementação de geleia real no processo de espermatogênese utilizando camundongo (Mus musculus) como modelo experimental. 2007. 33f. Monografia (Graduação em Ciências Biológicas) - Centro de Ciências da Saúde. Centro Universitário do Leste de Minas Gerais, Ipatinga, 2007.

MORAIS, A.C.T.; BARBOSA, L.P.; NEVES, M.M. et al. Parâmetros morfofisiológicos testiculares de camundongos (Mus musculus) suplementados com geleia real. In: CONGRESSO BRASILEIRO DE REPRODUÇÃO ANIMAL, 17., 2007, Curitiba. Anais... Belo Horizonte: CBRA.
OKA, H.; EMORI, Y.; KOBAYASHI, N. et al. Suppression of allergic reactions by royal jelly in association with the restoration of macrophage function and the improvement of Th1/Th2 cell responses. Internat. Immunopharm., v.1, p.521-532, 2001.

PAULA, T.A.R. Estudo histológico quantitativo da atividade espermatogênica de cães SRD. em diferentes faixas etárias após a puberdade. 1992. 62f. Dissertação (Mestrado em Morfologia) - Instituto de Ciências Biológicas. Universidade Federal de Minas Gerais, Belo Horizonte, 1992.

PAULA, T.A.R. Avaliação histológica e funcional do testículo de capivaras adultas (Hydrochoerus hydrochaeris). 1999. 84f. Tese (Doutorado em Biologia Celular) - Instituto de Ciências Biológicas. Universidade Federal de Minas Gerais, Belo Horizonte, 1999.

SALAZAR-OLIVO, L.A.; PAZ-GONZÁLEZ, V. Screening of biological activities in honeybee (Apis mellifera) royal jelly. Toxicology in Vitro, v.19, p.645651,2005

SARTI, P. Avaliação morfomométrica do testículo e da espermatogênese de jaguatiricas (Leopardus pardalis, Linnaeus, 1758) adultas. 2006. 56f. Dissertação (Mestrado em Medicina Veterinária) Departamento de Medicina Veterinária. Universidade Federal de Viçosa, Viçosa, 2006.

TOWNSEND, G.F.; MORGAN, J.F.; TOLNAI, S. et al. Morphometric studies on rat seminiferous tubule. Am. J. Anat., v.165, p.13-25, 1982. 